San Jose State University

SJSU ScholarWorks

Master's Theses

Master's Theses and Graduate Research

1991

\title{
Effects of uncertainty in illness on self-monitoring of blood glucose and glycemic control in non-insulin dependent diabetics
}

Karen M. Brown

San Jose State University

Follow this and additional works at: https://scholarworks.sjsu.edu/etd_theses

\section{Recommended Citation}

Brown, Karen M., "Effects of uncertainty in illness on self-monitoring of blood glucose and glycemic control in non-insulin dependent diabetics" (1991). Master's Theses. 98.

DOI: https://doi.org/10.31979/etd.3dsz-h98a

https://scholarworks.sjsu.edu/etd_theses/98

This Thesis is brought to you for free and open access by the Master's Theses and Graduate Research at SJSU ScholarWorks. It has been accepted for inclusion in Master's Theses by an authorized administrator of SJSU ScholarWorks. For more information, please contact scholarworks@sjsu.edu. 


\section{INFORMÄATON TO USERS}

This manuscript has been reproduced from the microfilm master. UMI films the text directly from the original or copy submitted. Thus, some thesis and dissertation copies are in typewriter face, while others may be from any type of computer printer.

The quality of this reproduction is dependent upon the quality of the copy submitted. Broken or indistinct print, colored or poor quality illustrations and photographs, print bleedthrough, substandard margins, and improper alignment can adversely affect reproduction.

In the unlikely event that the author did not send UMI a complete manuscript and there are missing pages, these will be noted. Also, if unauthorized copyright material had to be removed, a note will indicate the deletion.

Oversize materials (e.g., maps, drawings, charts) are reproduced by sectioning the original, beginning at the upper left-hand corner and continuing from left to right in equal sections with small overlaps. Each original is also photographed in one exposure and is included in reduced form at the back of the book.

Photographs included in the original manuscript have been reproduced xerographically in this copy. Higher quality $6^{\prime \prime} \times 9^{\prime \prime}$ black and white photographic prints are available for any photographs or illustrations appearing in this copy for an additional charge. Contact UMI directly to order.

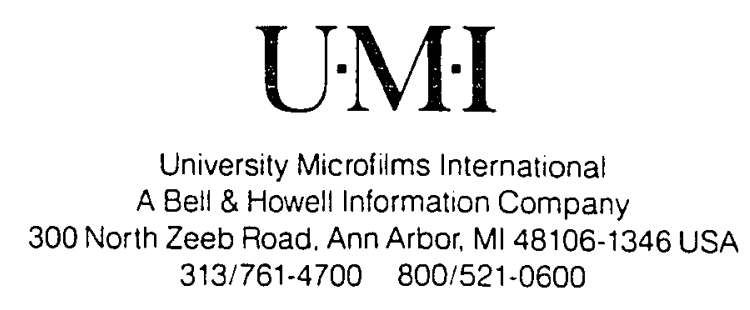



Effects of uncertainty in illness on self-monitoring of blood glucose and glycemic control in non-insulin dependent diabetics

Brown, Karen M., M.S.

San Jose State University, 1991 



\title{
EFFECTS OF UNCERTAINTY IN ILLNESS \\ ON SELF-MONITORING OF BLOOD GLUCOSE \\ AND GLYCEMIC CONTROL IN \\ NON-INSULIN DEPENDENT DIABETICS
}

\author{
A Thesis \\ Presented to \\ The Faculty of the Department of Nursing \\ San Jose State University
}

In Partial Fulfillment

of the Requirements for the Degree

Master of Science

BY

Karen M. Brown

May, 1991 
APPROVED FOR THE DEPARTMENT OF NURSING
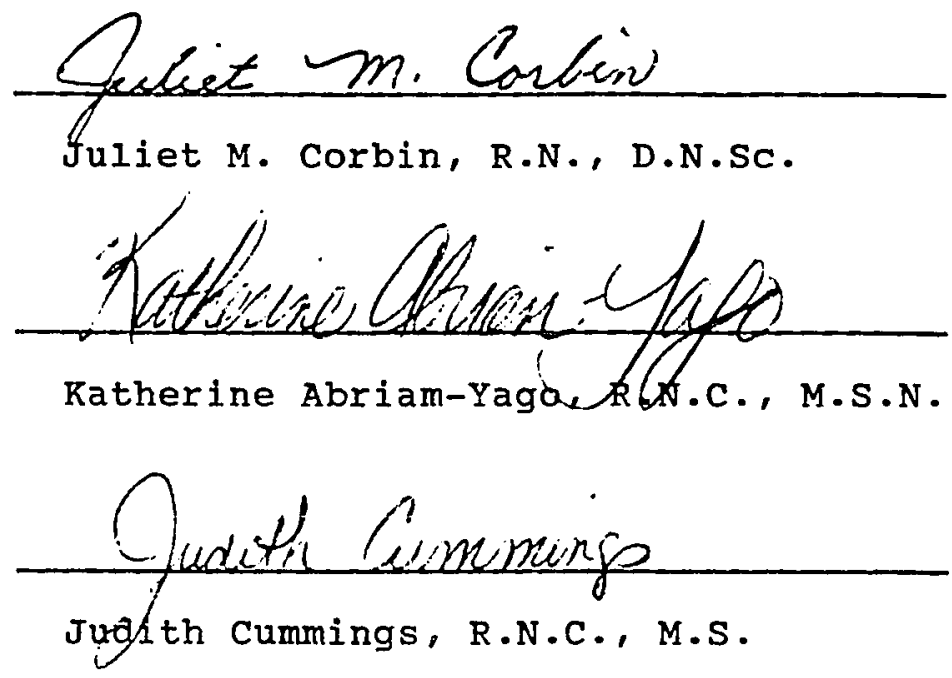

APPROVED FOR THE UNIVERSITY

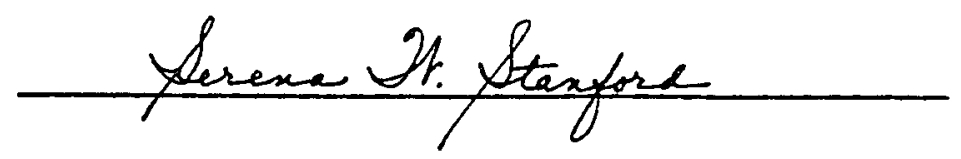




\begin{abstract}
ACKNOWLEDGMENTS
To Dr. Juliet Corbin, San Jose State Unfversity, who shared so much time guiding me through this project.

To Dr. Kathleen Roe, San Jose State University, who shared her knowledge and expertise, and made learning the research process an exciting challenge.

To my husband, Scott, and daughters, Bevin and Erin, whose love gives me courage and encouragement every day.
\end{abstract}




\section{ABSTRACT}

EFFECTS OF UNCERTAINTY IN ILLNESS ON SELF-MONITORING

OF BLOOD GLUCOSE AND GLYCEMIC CONTROL IN

NON-INSULIN DEPENDENT DIABETICS

by Karen M. Brown

This study explores the influence of perceived uncertainty in illness on performance of blood glucose self-monitoring and adequacy of glycemic control in non-insulin dependent diabetics. A non-experimental correlational design was used.

A convenience sample of eighteen non-insulin dependent diabetic men was selected. Respondents were interviewed for demographic data and were questioned about their use of self-blood glucose monitoring (SBGM). Participants then completed the Mishel Uncertainty in Illness scale. Participants' most recent $\mathrm{HbA} 1 \mathrm{c}$ results were obtained from the medical center's computerized laboratory data.

A Pearson product-moment correlation was used to determine the presence and direction of relationships between the major variables. A significant negative relationship was found between the measure of uncertainty and adequacy of glycemic control in this sample. A non-significant, negative relationship was obtained between uncertainty and the frequency of performing SBGM. The relationship between SBGM and adequacy of glycemic control approached but did not attain significance. 
TABLE OF CONTENTS

Page

LIST OF TABLES • . . . . . . . . . . . . . . . vii

IIST OF FIGURES . . . . . . . . . . . . . . . . . . vili

Chapter

1. INTRODUCTION . . . . . . . . . . . . . 1

The Problem and Research Questions . . . . 1

Purpose and Need . . . . . . . . . . 5

Definition of Terms. . . . . . . . . 6

Assumptions. . . . . . . . . . . . 8

Research Design. . . . . . . . . . . 9

Scope and Limitations. . . . . . . . . 9

2. THE CONCEPTUAL FRAMEWORK AND REVIEW

OF RELATED LITERATURE • . . . . . . . . . 11

The Conceptual Framework . . . . . . . . 11

The Review of Related Literature . . . . . 13

3. THE METHOD . . . . . . . . . . . . . 27

Research Procedures. . . . . . . . . 28

Instruments. . . . . . . . . . . . 30

Data Analysis. . . . . . . . . 34

4. ANALYSIS AND INTERPRETATION OF DATA. • . • . 37

Description of the Sample. . . . . . . 37

MUIS Scores. . . . . . . . . . . . 40

Analysis of Internal Consistency . . . . . 43

Analysis Related to the Research Questions • 44 
5. CONCLUSIONS AND RECOMMENDATIONS. . . . . . 50

Summary of Major Findings. . . . . . . 50

Explanation of the Results from the

Perspective of the Conceptua? Framework. . 52

Limitations to Generalizability. . . . . . 54

Recommendations. . . . . . . . . . 54

REFERENCES. . . . . . . . . . . . . . . . . 58

APPENDICES

A. Human Subjects Approval,

Stanford University . . . . . . 65

B. Institutional Review Board Approval,

San Jose State University . . . . . 67

C. Consent Letter . . . . . . . . . 69

D. Interview/Questionnaire Form . . . . . 74

E. Mishel Uncertainty in Illness Scale . . 76

F. Permission to use the Mishel

Uncertafinty in IIIness Scaie. . . . . 81 


\section{LIST OF TABLES}

Table

Page

1. Description of Sample . . . . . . . . . 38

2 MUIS Scores . . . . . . . . . . . . 41

3. Correlations between MUIS Scores,

SBGM Performance, and HbAlc levels. . . . 45

vii 


\section{LIST OF FIGURES}

Figure

Page

1. Relationship of $\mathrm{HbA}$ ic levels with

$$
\text { MUIS SCORES . . . . . . . . . . . . . } 47
$$

2. Relationship of SBGM with HbAlc

$$
\text { Results . . . . . . . . . . . . } 49
$$


Chapter 1

INTRODUCTION

The Problem and Research Questions

Non-insulin dependent diabetes meliitus (NIDDM) is a chronic disease with long and short term complications that are believed to be related to adequacy of blood glucose control (Froesch, Assal, \& Liniger, 1986, pp. 805-818; Peterson, McLean, \& Senator, 1984; Tchobroutsky, 1978). Attaining this control is a complex process that often demands a commitment to major behavior and lifestyle changes for non-insulin dependent diabetics. These can include: adherence to a prescribed diet; welght reduction; taking insulin injections or oral antidiabetic medications; increased exercise; and often, regular self-monitoring of blood glucose (Froesch et al., 1986, p. 776).

Diabetics are expected to adopt and maintain these new behaviors for the remainder of their lives, despite many obvious and not-so-obvious hinarances to change. Diabetes is not characterized by compeling and specific disabilities that may enhance motivation to perform prescrlbed behaviors in other diseases (Sackett \& Snow, 1979). Furthermore, diabetes, like other chronic ilinesses, requires permanent changes in lifestyle. Since the likelihood of being diagnosed with NIDDM increases with 
age, the demands to change behaviors are being made on middle-aged and older adults. It is possible that they have established lifestyle patterns, dietary customs, and activity levels that are resistant to change (Haefner \& Kirscht, 1970) and that even may have contributed to their developing diabetes.

It is not surprising, then, that diabetics' adherence to dietary and other care recommendations is at or less than 50\% (Cerkoney \& Hart, 1980; Christensen, Terry, wyatt, Pichert, \& Lorenz, 1983; Korhonen et al., 1983; Williams, Anderson, Watkins, \& Coyle, 1967). Extended, long-term care regimens typical of chronic illnesses have a lower compliance rate than acute care treatments (Ekerling \& Kohrs, 1984; Sackett \& Snow, 1979). Accordingly, frequency of self-monitoring of blood glucose has been shown to decrease over time (Fox et al., 1984; Wing, Epstein, Nowalk, Scott, \& Koeske, 1985).

Numerous studies have been done examining factors related to adherence to prescribed self-care regimens in diabetes. These include: (a) the effects of health beliefs, (b) locus of control, (c) psychological or social factors, and (d) patient tedium and burnout. Another subtle, but important factor that may influence diabetics' adherence to self-care behaviors is perceived uncertainty 
regarding current treatments as well as uncertainty regarding future course of iliness.

Diabetes has a course that may vary widely between patients as to which complications will occur and how disabling they will be, thus making the course uncertain. There is also a wide range of clirical symptoms associated with diabetes in both the hypo- and hyperglycemic states, and the client may even be asymptomatic (Froesch et al., 1986, p. 792).

The symptoms of diabetes are often ambiguous and indirect, such as fatigue, restlessness, or weight loss. These ambiguous symptoms, or lack of symptoms, might cause uncertainty or doubt as to whether the diagnosis of diabetes is correct, and thus influence the quality or level of self-care participation. Lack of specific and compeliing symptoms may also promote a belief that complications will not occur, and interfere with regimen adherence (Ekerling \& Kohrs, 1984). Uncertainty as to the meaning of diabetic symptoms, or uncertainty as to how to manage them, may prompt diabetics to choose ineffective symptom relief measures or choose actions that may worsen the blood glucose level (Hamera et al., 1988). Furthermore, the range of treatments for non-insulin dependent diabetics is varied, and may be an additional 
source of uncertainty. Diabetics may be given vague suggestions on how to control their disease course such as to lose a few pounds or to avoid sugar in their diet (Glasgow, Wilson, \& McCaul, 1985). Others may be given a complex regimen that includes insulin injections, a strict calorie or exchange diet, an exercise prescription, and four or more self-blood glucose tests daily (Froesch et a1., 1986, pp. 776-788, 800). Uncertainty caused by the complexity of treatment regimens, vague or unclear care instructions, or lack of confidence in the value of the treatments in controlling their diabetes might also influence adherence to self-care prescriptions (Price, 1988 , p. 104).

Many factors may influence diabetics' participation in self-care behaviors. Of these, uncertainty is probably the least studied and least understood. More information is needed about the potential influence of uncertainty on self-care practices and metabolic control in non-insulin dependent diabetics.

Three questions were developed for this study:

1. Is there a relationship between perceived uncertainty in illness and the frequency of performance of self-blood glucose monitoring in non-insulin dependent diabetic men? 
2. Is there a relationship between perceived uncertainty in illness and the adequacy of glycemic control in non-insulin dependent diabetic men?

3. Is there a relationship between frequency of self-blood glucose monitoring and glycemic control in non-insulin dependent diabetic men?

Purpose and Need

The purpose of this study is to explore the relationships between uncertainty in illness, blood glucose self-monitoring, and long-term glycemic control in non-insulin dependent diabetic adults. This study will provide information on the relationships between uncertainty and illness management behaviors in non-insulin dependent diabetics. This knowledge will enable nurses to determine appropriate and needed areas of patient education and/or counseling, and to provide support to diabetics in their efforts to cope with their illness.

This study also will increase nurses' understanding of the impact of the phenomena "trajectory projection," "trajectory scheme," "trajectory management," and "reciprocal impact" as described by corbin and strauss (1988). Knowledge about relationships between these aspects of their model will provide a basis for a more specific focus of nursing interventions in relation to 
their patients' trajectory projections and trajectory management plans (Corbin \& Strauss, in press). If trajectory projection is indeed a basis for patient illness management, it is very important that patients be given sufficient information and problem solving skills so that they make more realistic projections and devise optimal management schemes.

\section{Definition of Terms}

For the purpose of this study, the following definitions apply:

1. Non-insulin dependent diabetes was formerly classified as Type II or adult-onset diabetes. This condition most frequently occurs in obese adults. As with other types of diabetes meliitus, the goal of treatment is to maintain normal blood glucose levels. Diet is the cornerstone of treatment, but insulin or oral hypoglycemic agents may be required to maintain optimal blood glucose levels (Froesch et a1., 1986, p. 776).

2. Blood glucose selE-monitoring is the process by which patients evaluate their own level of blood glucose by pricking a fingertip with a sterile lancet, placing a drop of blood on an enzyme-impregnated strip, and determining blood glucose concentration by comparing the degree of color change in the strip against a color scale or 
inserting the strip into an electronic device manufactured for reading the strips (Gilden, 1988).

3. Glycosylated hemoglobin $\left(\mathrm{HbA}_{1 \mathrm{C}}\right)$ is a laboratory test by which blood can be analyzed for average blood sugar level for the previous 60 days (Skelton, 1986).

4. Uncertainty is a cognitive state created when an event cannot be adequately structured or categorized because sufficient cues are lacking (Budner, 1962). In this study, uncertainty is operationally defined by the participants' responses to the Mishel Uncertainty in Illness Scale.

5. Illness Trajectory is the course of a chronic iliness as it progresses over time. This illness course can be shaped and managed (Corbin \& Strauss, in press).

6. Trajectory projection is the image of the potential shape the course of illness and iis outcome will take over time. This includes the effects of the iliness, its treatments, and the behaviors needed to manage it (Corbin \& Strauss, in press).

7. Trajectory scheme is the management plan, developed on the basis of the trajectory projection, to shape the iliness course and outcome (Corbin \& Strauss, in press). 
8. Trajectory management is the process by which an illness course is shaped, through all of the illness phases, by the trajectory scheme (Corbin \& strauss, in press).

9. Reciprocal impact is the consequence component of the Trajectory Framework, and represents the complex interaction between 1llness, biographical considerations, and every day activities (Corbin \& Strauss, in press). Assumptions

Th research study was based upon the following assumptions:

1. The respondents would respond honestiy and candidly to both the Uncertainty in Illness scale, and questions regarding their performance of self-blood glucose monitoring.

2. Uncertainty experienced by diabetics may (a) shape the individual's trajectory projection; (b) influence the trajectory scheme and illness management behavior choices; and (c) have consequences for adequacy of glycemic control, and possible long-term complications.

3. The Mishel Uncertainty in Illness Scale is a valid measure of uncertainty and represents one of several possible variables that may influence trajectory projection. 
Research Design

This non-experimental, exploratory study was designed to determine the presence and direction of relationships between the independent variable of uncertainty in iliness, and the dependent variables of frequency of self-blood glucose monitoring and adequacy of glycemic control.

The convenience sample consisted of eighteen nor-insulin dependent diabetics who were awaiting routine appointments in the Nurse-run Diabetes Clinic and/or the Endocrine Clinic of a Northern California V.A. Medical Center. Respondents were interviewed for demographic data and were questioned about their performance of self-blood glucose monitoring. Participants then completed the Mishel Uncertainty in Illness Scale and their most recent HbAlc results were obtained from the medical center's computerized laboratory data. A Pearson product-moment correlation was used to determine the presence and direction of relationships between major variables.

Scope and Limitations

The generalizability of the findings of this study may be limited for the following reasons:

1. The presence of other chronic conditions may have influenced participants' responses to the uncertainty scale. 
2. Participants' blood glucose control may have been influenced by unknown physiologic or emotional factors in addition to uncertainty.

3. A convenience rather than random sample was used.

4. The number of people who met the study's admission criteria, and who consented to participate, was smaller than expected. 
Chapter 2

CONCEPTUAL FRAMEWORK AND REVIEW OF RELATED LITERATURE

The Conceptual Framework

The conceptual framework for this study is the Trajectory Framework for Chronic Illness Management (Corbin \& Strauss, 1988). This model was developed to increase understanding of the problems associated with chronic iliness and its management.

Adherence to prescribed treatments is not a central feature of this model. However, an important aspect of the Trajectory Framework is the concept that a chronic illness is shaped and managed over time. This shaping occurs through interactions between conditions arising from the iliness experience, illness management behaviors, and biographical factors that define one's personal, family, social, and work life.

Diabetes management fits well when studied from the perspective of the Trajectory Framework. Compared to those with other chronic conditions, such as Parkinson's disease or multiple sclerosis, diabetics have a more apparent opportunity to manage and shape the course and outcome of their iliness. Studies of factors that influence diabetics' particlpation in trajectory management should guide interventions to promote optimal day-to-day 
management as well as decrease the occurrence of long-term complications.

According to the Trajectory Framework, one aspect of the illness experience that may influence the shaping process is the development of a "trajectory projection" (Corbin \& Strauss, 1988, pp. 38-41). Formation of this mental image includes envisioning the effects of the iliness and the effects of its treatments on one's future life. The trajectory projection is influenced by several factors including the ill person's knowledge and beliefs about the illness and his expectations of the course of illness (Corbin \& Strauss, 1988, pp. 38-41).

This projection is the basis for developing a "trajectory scheme": the decisions and behaviors related to illness management (Corbin \& Strauss, 1988, pp. 41-42). Uncertainty may interfere with formation of an accurate or meaningful trajectory projection, and thus may influence illness management behaviors and ultimately shape the disease course and outcome.

For example, if one has an accurate projection (including accurate and clear information on how to attain optimal blood glucose control and avoid long-term complications), the level of certainty will possibly influence one to plan management behaviors according to 
that projection. On the other hand, if one is uncertain about his ability to make effective day-to-day management decisions or is uncertain about his ability to shape the course and outcome of the illness, it is less likely that he will be to develop and carry out an effective scheme. Uncertainty about the manageability of an illness, or lack of guidance on how to manage, makes it difficult to make an accurate projection. Uncertainty may therefore result in less optimal management strategies, poorer blood glucose control, and greater numbers of complications. The Review of Related Literature Regimen adherence and glycemic control

Compliance to diabetes management activities has been the subject of hundreds of research articles. It is difficult to compare the results of these studies because of differences in sample type and size, research methods used, and variables measured. Most of the research was done on insulin-dependent diabetics, who differ from non-insulin dependent diabetics in age, metabolic status, treatment strategy, and complication rates.

Also, many studies of compliance utilized measures of non-equivalent care behaviors, such as medication, diet, and blood or urine testing, to derive a total compliance score. Comparison of non-equivalent behaviors may impair 
validity. As illustrated by Glasgow, Wilson, and MCCaul (1985), "is conducting 3 of 4 daily glucose tests equivalent to taking $75 \%$ of one's shots on time or exceeding a calorie consumption goal by 25\%?" Assigning a total compliance score for several diverse behaviors may also reduce validity, as compliance to one aspect of the care regimen is frequently unrelated to adherence to other aspects of care performance (Schafer, Glasgow, McCau1, \& Dreher, 1983).

Comparison is made even more difficult because diabetes care recommendations are individual and varied in content, as well as in the quality with which they are presented by physicians or nurses, and received or understood by patients. Glasgow et al. (1985) argue that there is a construct validity problem in studying compliance in diabetes care. They observe that some aspects of care regimens may have been non-specific ("lose some weight"), not clearly communicated, or not communicated at all.

They and others (Dunbar \& Strunkard, 1979) argue that the concept of compliance is value-laden and has little meaning unless accompanied by a specific prescription for medication or care activities. Glasgow et al. (1985) recommend the phrase "level of self-care behaviors," as 
this better conveys the idea that the frequency or consistency of specific regimen behaviors can influence glycemic control regardless of what was prescribed. Finally, some studies have shown little or no relationship between compliance with prescribed behaviors and physiologic control in diabetes (Diehl, Bauer, \& Sugarek, 1988; Glasgow, McCaul, \& Schafer, 1987) and other chronic illness (DeVon \& Powers, 1984). This would suggest that research on health care behaviors directed at improving glycemic control would be more useful to clinicians if the behavior was shown to influence glycemic control in each sample studied.

Among the compliance studies of adult-onset or non-insulin dependent diabetics, only a handful also present data on the level of physiologic control in their sample. Three of these studies use or test the health belief model to look for possible relationships and explanations or predictions of diabetics' adherence to care regimens and level of metabolic control (Peterson, Mclean, \& Senator, 1987; Harris, Skyler, Linn, Pollock, \& Tewksbury, 1982; Harris \& Linn, 1985). These studies show mixed results in finding significant relationships between the level of subjects' health beliefs and the degree of adherence to health behaviors and glycemic control. 
Harris and Linn (1985) found that health beliefs did not predict compliance significantly. Severity was the only aspect of the health belief model that was significantly but weakly related to compliance. This study found a significant relationship between health beliefs and metabolic control among their sample, leading these authors to speculate that health beliefs are more strongly associated with physiologic functioning than with health-oriented behavior.

The authors used a total compliance score based on participants' self-report of medication use, diet, exercise, foot care, and urine testing. A nurse compared each subject's report against the care recommendations on their medical chart. The use of each participant's individual care recommendations made the study of compliance appropriate. However, rather than studying the value of performance of each area of care separately, the nurse assigned a rating from 1 (very compliant) to 4 (very non-compliant), and a total of the five items was used to compute an overall compliance score which was used in the statistical tests against control and health bellefs.

As mentioned previously, comparison of non-equivalent aspects of care behaviors may not be a valid measure of patient adherence as each of these aspects of care may not 
equally influence diabetic control. Furthermore, how the nurse rated participants who exceeded care by exercising or urine testing more often than was prescribed is not known. Some studies have considered any deviation from the prescribed regimen to be indicators of non-compliance, regardless of the nature of the behavior (Glasgow et al., 1985).

In another study of 50 adult-onset diabetics, Harris, Skyler, Linn, Pollock, and Tewksbury (1982) found a significant correlation between compliance and perceived susceptibility and perceived barriers, but insignificant relationship between compliance and perceived severity. Perceived susceptibility, severity, and perceived benefits were found to be significantly related with physiologic control. Again, a composite score rating of several care behaviors was used to label patients as compliant and non-compliant, rather than considering the value of the behaviors individual1y.

Peterson, McLean, and Senator (1987) studied perceived importance of compliance and ease of compliance, which were quite similar to the measures of benefits and barriers of the care regimen that is used in the health belief model. Although they found a significant relationship between importance and ease of performing the 
care regimen and compliance, these were not significantly related to glycemic control in their sample. These authors did consider the behaviors separately.

In this study, diabetic control was measured by use of a composite score of fasting glucose, urine glucose and the HbAlc. Both fasting glucose and urine glucose levels are transient, and can vary according to the patient's diet or exercise in the immediate previous days, stress level, fever or minor infection. The use of HbAlc has been reported to be a more stable indicator of the level of glycemic control for the previous eight to ten weeks as it is not influenced by diet or exercise in the immediate past (Froesch et a1., pp. 798-800; Skelton, 1986).

Diehl, Bauer, and Sugarek (1987) examined the relationship between demographic and socioeconomic factors, descriptors of the caregiving relationship between physician and patient, and compliance and control in their non-insulin dependent diabetic sample. They found that factors reflecting the care relationship were not significantly related to patient compliance or metabolic control. They also found that only older age and greater education were related to compliance, but not to level of fasting blood sugar levels. Again, the use of HbAlc 
would give a more meaningful picture of long-term glycemic control.

Finally, wilson et al. (1986) looked at the effect of psychosocial features as predictors of self-care behaviors and glycemic control in a sample of 184 non-insulin dependent diabetics. They found that compliance to self-care behaviors was significantly related to psychosocial and demographic variables, but not significantly related to glycemic control in their sample. These authors used subjects' estimation of the percentage of time they performed self-care behaviors as instructed by their physicians. Each subject's individual prescription was used as a standard. The authors recognized that this method might not provide an accurate picture of prescribed regimen. However, they felt it did assess each subject's representation of appropriate self-care behaviors. Glycemic control was measured by $\mathrm{HbA} I \mathrm{c} \cdot$

\section{Self-monitoring of blood glucose}

The practice of self-monitoring of blood glucose (SMBG) for diabetics has become an increasingly accepted part of routine and prudent health behaviors since the late 1970's. Once reserved for insulin-dependent and pregnant diabetics, self-monitoring of blood glucose is now encouraged for all 
diabetics who strive for improved control, whether they use insulin, oral hypoglycemic agents, or are controlled by diet (American Diabetes Association, 1985; Froesch et al., p. 800$)$.

SMBG has the advantage of immediate feedback, which allows diabetics to evaluate the effects of changes in diet, exercise, and stress level. Although some studies have not shown SMBG to improve compliance in other areas of diabetes management (Wing, Epstein, Nowalk, Scott, \& Koeske, 1985), the use of this technique has been reported to improve glycemic control in children (Saucier, 1984), insulin-dependent diabetic adults (sjobert, Carlson, Rosenqvist, \& Ostman, 1988), and non-insulin dependent adults (Gilden, 1988). Furthermore, the use of SMBG was found to influence diabetics' perception of their disease by confirming that they have diabetes, and giving them more tangible feedback on their metabolic state (Fox et al., 1984).

\section{Uncertainty}

The influence of uncertainty on the trajectory projections or trajectory schemes of non-insulin dependent diabetics is not known. No studies have been done to determine the effect of uncertainty on diabetics' adherence to self-care behaviors, disease course, or outcome. 
However, studies have been done on the impact of uncertainty on stress, coping methods, and occurrence of illness in various other populations.

Suls and Mullen (1981) examined the impact of adverse controllable and uncontrollable life events on the occurrence of iliness. Their results indicated that both undesirable uncontrollable events and undesirable events of uncertain controllability were significantly related to the occurrence of iliness. However, the events of uncertain controllability were more strongly related to illness than events perceived as totally uncontrollable. The sample used in this study was 126 undergraduate university students. This sample cannot be used to generalize to a chronically ill population, but the findings do indicate that uncertainty may augment the stressful impact of an undesirable event.

Forsythe, Delaney, and Gresham (1984) studied the processes used by hospitalized chronically ill patients to cope with the demands of unpredictable and progressive disease. The goals of this qualitative study was to assess the effect of chronic illness on a person's lifestyle and identify particular needs arising from the event of hospitalization. 
The following concerns were identified from the participants' responses: (a) uncertainty, which influenced patients' perception and definition of their iliness; (b) unpredictability of disease process; (c) day-to-day effectiveness of treatments (as with effectiveness of pain control in arthritis); and (d) effectiveness of treatments over the long run, (for example, influencing the course or outcome of multiple sclerosis). A major goal of these patients was to diminish uncertainty. Although this study did not differentiate the responses of people with various chronic diseases, the ldentification of uncertainty as a major concern throughout the sample indicates a need for further study of the effects of uncertainty.

Price (1988) explored the experience of uncertainty related to the management trajectory in diabetes. In this qualitative study, particlpants were interviewed with the purpose of identifying aspects of iliness management that were disruptive or confusing due to uncertainty. This author defined uncertainty as "when not knowing disrupts meaning or coherence of a personally salient situation" (Price, 1988, p. 4).

Processes identified from the interview data of 19 Insulin-managed diabetics fell into two sequential categories. These were: (a) learning to manage ("getting 
regulated") and (b) maintaining management ("being regulated"). Additional sequential sub-phases were identified in both of these categories.

Uncertainty, as indicated by expressions of confusion or need for knowledge, were evident in each phase of the management trajectory. Uncertainty was revealed in vignettes of patients describing their efforts to learn about diabetes and how to fit the disease and its management into their lives. Uncertainty was expressed in both concrete terms, such as learning to adjust insulin dosage or develop an appropriate diet, to emotional issues of pondering the effects of their diabetes management on family life, or fitting their diabetes management plans into other social situations.

In quantitative nursing research on uncertainty, Mishel (1981, 1984) investigated the relationship of perceived uncertainty and stress experienced in hospitalized patients. The author developed and used the Mishel Uncertainty in IIIness Scale (MUIS) to measure perceived uncertainty in illness. Findings indicate a strong relationship between uncertainty and stress. Mishel used a variety of hospitalized patients with diagnoses including cancer, heart disease, stroke, and "progressively deteriorating conditions," which all have 
a poorly defined course and ambiguous outcomes. Diabetes was not one of the diseases studied. In her conclusion, Mishel stated that some of the findings may have been influenced by the multiplicity of diagnoses, and suggested further work on the effects of uncertajnty in specific patient populations.

The effects of uncertainty in post-myocardial infarction patients was studied by Webster and Christman (1988) and Christman et al. (1988). Noting several uncertainties surrounding the course, treatment, and outcome of myocardial infarction (MI), Webster and Christman (1988) studied the effects of uncertainty on MI patients' level of emotional distress and choice of affective versus problem-solving coping methods. Increased levels of uncertainty were found to be significantly related to anxiety and depression following a myocardial infarction. Their findings only weakly supported their hypothesis that higher levels of uncertainty would influence the cholce of affective versus problem-solving coping methods. The authors felt that their small sample size contributed to the weak findings, and that this study does provide initial information on the effects of uncertainty in the post-MI period. 
Christman et a1. (1988) studied the influence of uncertainty in illness and choice of coping behaviors on emotional distress and physical recovery after an MI. The authors measured changes in uncertainty, choice of coping methods, distress levels and physical recovery indicators. These measurements were taken within 72 hours of hospital discharge, one week after discharge, and four weeks after discharge.

Findings indicate that high levels of uncertainty were directly related to high levels of emotional distress during the post-hospitalization period. Uncertainty was also found to be a significant influence on the physical activity measure, but only during the first week after hospital discharge. The influence of uncertainty on physical activity decreased to an insignificant level by the fourth post-discharge week. Both Webster and Christman and Christman et al. used the MUIS as a measure of uncertainty in their research.

Bidnick (1986) examined the relationship between perceived uncertainty and adaptation to chronic low back pain. This author used the MUIS as a measure of perceived uncertainty and the Sickness Impact Profile to determine the degree of adaptation achieved in her sample. A strongly significant, negative relationship was found 
between perceived uncertainty and adaptation to pain: increases of perceived uncertainty were accompanied by decreases in adaptation scores. The complexity subscale was found to bear the most influence on the adaptation scores.

The author concluded that nurses can utilize these findings to maximize adaptation potential of patients with chronic back pain. Assessing uncertainty regarding diagnosis, treatment, or prognosis; teaching patients about the physiological causes of back pain; and teaching appropriate interventions may all serve to decrease uncertainty and thus increase the level of adaptation. Summary

In the past decade, there has been a significant interest in learning about both the causes and the effects of uncertainty in illness. However, further studies are needed to fully understand the significance of uncertainty in illness management and ways nurses can intervene to reduce any negative impact. This study explored the effects of uncertainty in illness on the frequency of self-blood glucose monitoring and adequacy of glycemic control in non-insulin dependent diabetic adults. 


\section{Chapter 3}

THE METHOD

In order to discover the relationships between uncertainty in illness, performance of self-monitoring of blood glucose, and adequacy of glycemic control in non-insulin dependent diabetic men, 18 male NIDDM outpatients were studied. The particlpants were clients in a Nurse-run Diabetes Clinic and/or the Endocrine clinic at a V.A. Medical Center in Northern California. A standard procedure For many patients attending these clinics is to have a glycosylated hemoglobin ( $\mathrm{HbA}_{1 \mathrm{C}}$ ) drawn every three months, to evaluate their level of glycemic control. The criteria for inclusion in this study were: 1. Having a diagnosis of non-insulin dependent diabetes.

2. Being male.

3. Being oriented to person, place, and time.

4. Having the ability to read and complete the questionnaires independently, or the ability to understand the questions and communicate their responses to the interviewer verbally.

Approval to interview participants was requested from and was granted by the Human subjects committees at the 
V.A. Medical Center and San Jose State University (See Appendix A \& B). Clients were screened for the above criteria by the investigator after they checked into the clinic for their scheduled visit. All outpatient clinic users who met the criteria, and who attended the cilnic during the period of data collection, were invited to participate in this study. Eighteen people met the criteria, and were included in the study.

Research Procedures

Potential participants were approached as they waited for their Diabetes or Endocrine clinic appointment. The investigator introduced herself and described the study. Each participant was asked to review and sign a consent form, giving the investigator permission to interview him and to use his interview data, MUIS score, and HbAlc results in this study (See Appendix C).

If permission was granted, demographic data about each participant were obtained using a structured interview/questionnaire form that was developed by the investigator (See Appendix D). These data included: a) age, b) marital status, c) years of education, d) occupation, e) race, and f) level of income. The participants were also asked to list each of their medical problems or diagnoses, the date the problem was diagnosed, and to describe all 
treatment regimens prescribed for their diabetes and other medical problems. The clients were instructed to include al1 prescription diets, medications, and other activities used to care for their ilinesses.

The participants were then questioned about the frequency of performing blood glucose self-monitoring during the previous week. The participants were encouraged to state any times they missed performing a prescribed monitoring and any extra monitoring they did during the week .

The participants were then given written and verbal instructions on self-administration of the Mishel Uncertainty in IIlness Scale (see Appendix E). If a participant was able to read and self-administer the Uncertainty in Illness scale, he was then given time to do so. If problems with vision or the ability to read prevented self-administration, the investigator read each item and asked the participant to respond using the five response choices offered on the scale.

In order to make the MUIS more suitable to this sample of outpatient clinic patients, the phrase, "after you leave the hospital," was deleted from item number 18 . This same alteration was made in other research using clinic patients with the authorization of Dr. Mishel (Bidnick, 1986). The 
word "pain," used in items 4 and 7 , was changed to "symptom" as suggested by Dr. Mishel in the MUIS manual (Mishel \& Epstein, 1990).

Finally, the participant's most recent $\mathrm{HbA}_{1 \mathrm{c}}$ value was obtained from the medical center's computerized lab data. No lab test was administered solely for the purpose of this study.

Data collection was undertaken over a period of twelve weeks. The investigator attended the Diabetes and Endocrine clinics when they met each Thursday. Interviews were conducted with each participant privately as they waited for their clinic appointment.

Instruments

Two instruments were used in this investigation: the Mishel Oncertainty in Illness Scale (MUIS) and the demographic interview/questionnaire described in the previous section. The MUIS is a 34 -item questionnaire developed by Merle Mishel, Ph.D., R.N., of the University of Arizona. Permission to use the MUIS was requested and was granted by Dr. Mishel (see Appendix F).

The MUIS measures the level of perceived uncertainty pertaining to: diagnosis; meaning of symptoms; information from care providers; relationship with care providers; efficacy of treatments; prognosis; and system of care. 
This measure uses a 5-point Likert scale for rating responses to each item. Response choices range from strongly agree to strongly disagree.

The MUIS has demonstrated internal consistency reliability with a standardized alpha of .91 for the entire scale. This instrument has also been factor analyzed into four subscales. The following is a description of each subscale factor:

1. Ambiguity pertains to cues about the state of illness being vague, indistinct, and information tending to blur and overlap (Mishel \& Epstein, 1990). This is the largest factor, containing 17 items, with a standardized alpha of .91).

2. Complexity refers to the multiple and varied cues the patient perceives about treatment and the system of care (Mishel \& Epstein, 1990). This factor contains seven items and has a standardized alpha of .75).

3. Lack of information refers to an absence of shared or known information from care providers (Mishel \& Epstein, 1990). This is a four-item factor, with a standardized alpha of .71 .

4. Unpredictability refers to a lack of contingency between iliness and treatment cues and illness outcome 
(Mishel \& Epstein, 1990). This factor has six items, with a standardized alpha of .70 .

The above reliability data was current at the time this research project was initiated and reflects the version of the MUIS used in this study. The MUIS, developed in 1980, was initially standardized with hospitalized medical, surgical, and diagnostic patients. In subsequent research, the scale has been used with cancer, cardiac, and chronic illness populations (Mishel \& Epstein, 1990). Published uncertainty research in chronic illness includes persons with chronic airway obstruction, back pain, multiple sclerosis, cystic fibrosis, and end state renal disease. Uncertainty research with diabetes, asthma, and scleroderma are currently being conducted using the MUIS (Mishel \& Epstein, 1990).

With increased use, and with data becoming available from diverse populations, the reliabilities of factors 3 (lack of information) and 4 (unpredictability) were found to be unstable. The MUIS was reanalyzed, and a 30-item, four-factor structure emerged, but with some differences from the original scale.

With the addition of new items, the interpretation of factor 3 (lack of information) changed to inconsistency of information. The author defines this as "receiving 
information that either changes frequently or is not in accord with information previously recelved" (Mishel \& Epstein, 1990, pp. 3-4). The definition of the fourth factor (unpredictability) remained the same.

Reliabilities improved after the changes were made. The alpha coefficients were found to be in the moderate to high range for the first three factors. However, they remained at the borderline level for factor 4 . The author states this fourth factor has been retained for theoretical consideration (Mishel \& Epsteln, 1990).

Construct validity of the MUIS has been evaluated in research studies that tested theoretically proposed relationships regarding the perception of uncertainty in iliness. For example, the sensitivity of the MUIS was demonstrated by the scale's ability to distinguish between medical, surgical, and diagnostic work-up patient populations (Mishel, 1981). Dr. Mishel hypothesized that the perception of uncertainty would be greater during the diagnostic phase of illness because of the absence of a determined diagnosis. In this initial study, the MUIS scores confirmed the hypothesis at a significant level. Likewise, significantly higher levels of uncertainty were found in a sample of cardiac catheterization patients who were awaiting diagnosis than were found in a sample of 
hemodialysis patients who had a definite diagnosis (Mishel, 1981). The sensitivity of the MUIS has also been

demonstrated by its ability to distinguish between patients experiencing a sudden, new, and invasive diagnostic procedure as compared to those receiving familiar invasive treatment procedures (Mishel, 1981).

Support for the validity of the MUIS has been further demonstrated by other researchers' work (Mishel \& Epstein, 1990). These studies also propose theoretical relationships about the effects of uncertainty in iliness, antecedents of uncertainty, and the effectiveness of interventions to reduce the level of uncertainty. Findings indicate significant relationships between uncertainty and stress in illness; coping methods in illness; anxiety levels upon hospital discharge; psychosocial adjustment to illness; satisfaction with health care; and levels of depression. Convergent validity of the MUIS with a similar concept has been demonstrated by the finding of a very high correlation between the MUIS and a Comprehension of IIIness Questionnaire (Mishel \& Epstein, 1990).

Data Analysis

This was a non-experimental exploratory study designed to determine the presence and direction of relationships between major variables of uncertainty in illness, 
frequency of self-blood glucose monitoring, and adequacy of glycemic control in the selected sample. Variables of diagnosis of non-insulin dependent diabetes, gender, and ability to read or communicate responses to the questions were controlled by adherence to the selection criteria. Other variables, such as socioeconomic status, age, race, marital status, multiple illnesses, or number of medical treatments were not controlled for. However, questions regarding the above demographic variables were included in the interview questionnaire. This data offers a detailed description of this study's sample population for the purpose of comparison to other research samples. Data was analyzed for existence and direction of the relationships between the variables of uncertainty, frequency of self-monitoring of blood glucose, and level of glycemic control using correlational statistics. In compiling the data, the overall score of the MUIS was computed for each participant. A high score on the MUIS indicates a high level of uncertainty, and a low score indicates a low uncertainty level.

A Pearson product-moment correlation was used to determine the relationship between perceived uncertainty and the level of adherence to prescribed self-blood glucose monitoring tests. The level of adherence to this behavior 
was measured as the percentage of times the test was actually performed during the previous week versus the number of times it was prescribed.

A Pearson product-moment correlation was also used to determine the relationships between perceived uncertainty and adequacy of glycemic control, and between frequency of self-blood glucose monitoring and glycemic control. Each participant's most recent $\mathrm{HbA}_{1 \mathrm{c}}$ level was used to determine adequacy of blood glucose control. Descriptive statistics were used to analyze the demographic data. 
Chapter 4

ANALYSIS AND INTERPRETATION OF DATA

The purpose of this study was to measure the

relationships between perceived uncertainty, performance of self-blood glucose monitoring, and adequacy of glycemic control in non-insulin dependent diabetics. The following section presents the data and the analysis related to the research questions.

\section{Description of the Sample}

A sample consisting of 18 particlpants was obtained from two outpatient clinics at a Veterans Affairs Medical Center in Northern California. As outlined on Table 1, the mean age of the participants was 65.81 . The mean educational level for this sample was 12.33 years of schooling, a level slightly above that of a high school graduate.

Fifteen participants ( $83.33 \%)$ were married, one (5.56\%) never married, and two (11.11\%) were divorced. There were no vidowers. The ethnic composition of the sample included 13 Caucasian non-Hispanic (72.22\%); 3 Hispanic (16.67\%); 1 Black (5.56\%); and 1 Asian (5.56\%). Thirteen of the participants (72.22\%) were voluntarily retired, one (5.56\%) was retired due to disability, and four (22.22\%) were currently working. 


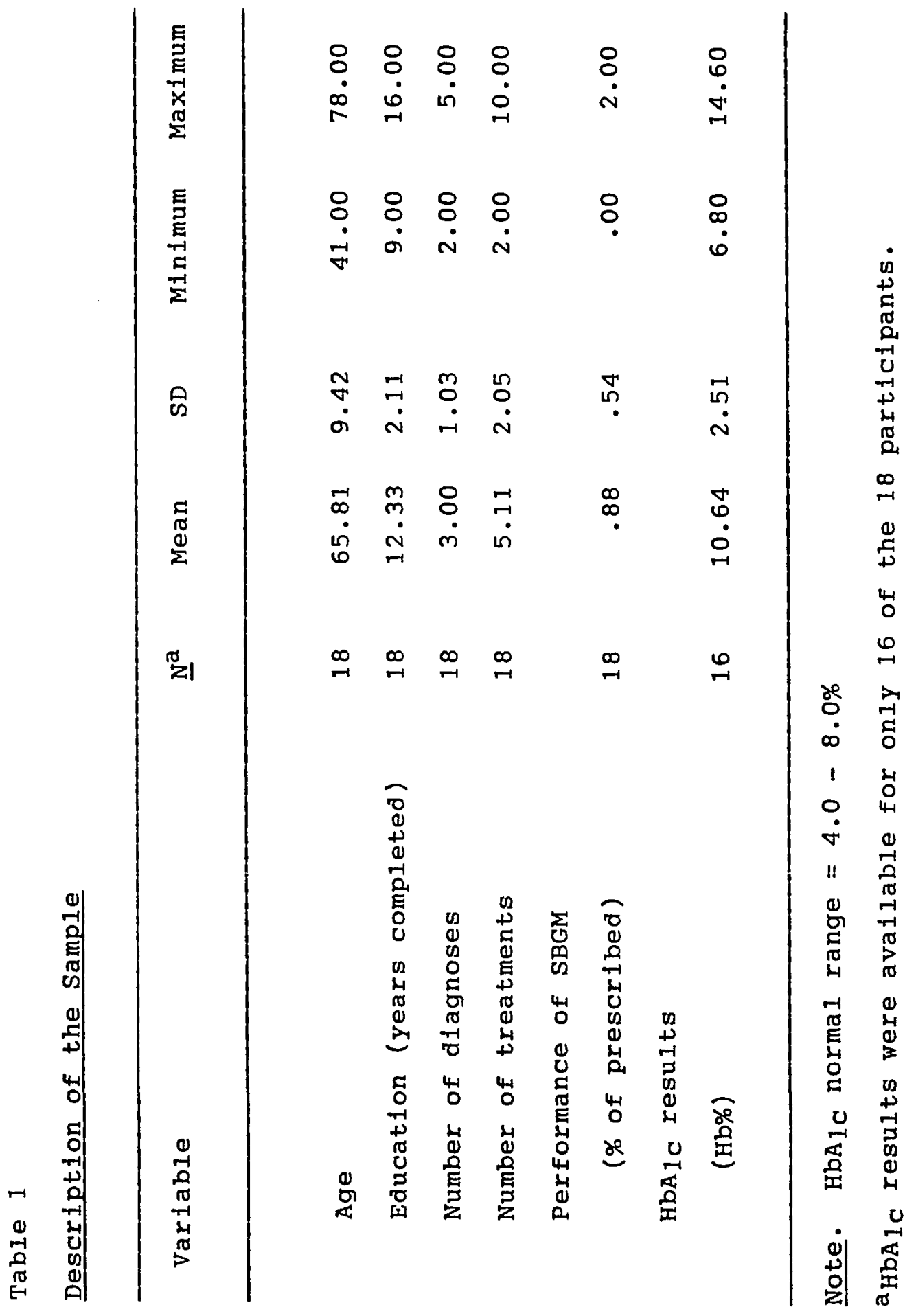


Income levels reported among the sample included one $(5.56 \%)$ at more than $\$ 50,000$ annual1y; one $(5.56 \%)$ between $\$ 40-\$ 50,000$; three $(16.67 \%)$ between $\$ 30-\$ 40,000$; none between $\$ 20-\$ 30,000$; six (33.33\%) between $\$ 10-\$ 20,000$, three (16.67\%) under $\$ 10,000$ annually; and four (22.22\%) declining to answer.

The length of time these participants had their diabetes ranged from four months to 30 years. The mean for this sample was 11.80 years since the time of their diagnosis of diabetes. Glycosylated hemoglobin levels were available for only 16 of the 18 participants. One of the participants, whose clinic appointment extended past the laboratory hours, was scheduled to have his HbAlc drawn at the time of his next clinic appointment. It was not yet drawn at the time of this study's data analysis. The other patient, who had several fasting glucose levels on file, had no record of the $\mathrm{HbA}_{1 \mathrm{c}}$ being ordered or drawn. HbAlc values obtained from the remaining 16 participants ranged from $6.80 \%$ to $14.60 \%$. The mean for this group was $10.64 \%$. Normal values for this test range from 4.0 to $8.0 \%$.

All 18 participants had health problems in addition to their diabetes. The total number of medical diagnoses for each participant (including their diabetes) ranged from two to five, with a mean of three for the sample. All of the 
additional diagnoses were chronic conditions. The most common were: coronary artery disease, listed by eight participants; hypertension, 1isted by four participants; and gout, stroke, renal failure, and ulcers, each mentioned by two participants.

Other 111nesses listed were hypertriglyceridemia, obesity, cancer, retinitis pigmentosa, glaucoma, cataracts, osteoarthritis, Paget's disease, rheumatold arthritis, depression, post-traumatic stress disorder, blindness due to diabetic retinopathy, chronic diarrhea, and hypotension. The number of prescribed regimens, for all of the diagnoses listed, ranged from two to ten. There was a mean of 5.11 treatment regimens for the sample.

\section{MUIS Scores}

To calculate the total MUIS score, each participant's responses to items 1 through 34 were scored according to the MUIS manual instructions. These scores were added up and the sum became the total MUIS score for the individual. The total MUIS scores can range from 34 to 170 . A high score indicates a high level of perceived uncertainty, and a low score indicates a lower level of perceived uncertainty .

Subscale scores were calculated by adding up the items designated as representing each subscale by the MUIS 


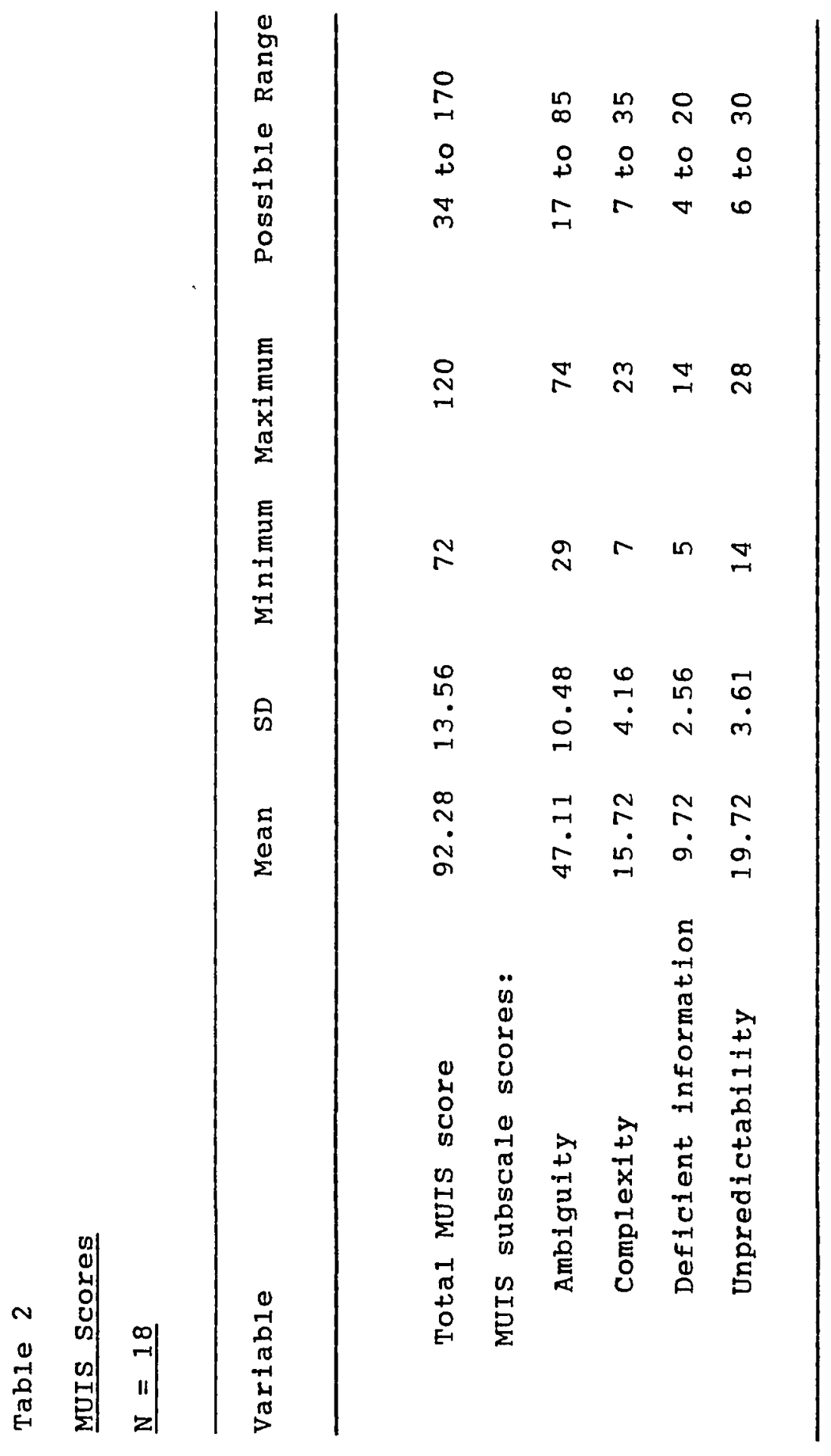


manual. Total scores and subscale scores for this sample of non-insulin dependent diabetics is outlined in Table 2. Definitions of each MUIS subscale factor are presented in Chapter 3 of this paper.

This sample's MUIS score means fell into the mid-range for possible scores in the total MUIS and for each of its subscales. Yet the mean of 92.28 for the total scale was higher than those collected by Dr. Mishel and other researchers for most other diagnostic categories (Mishel \& Epstein, 1990). For example, the mean total score for a sample labelled as "composite adult data," was 80.0 . The mean score for cardiac patients was 79.3 , and the mean score for cancer patients was 77.0 .

However, the higher scores of this study's sample is consistent with higher MUIS scores for other chronic illness samples reported by Mishel and Epstein (1990). Mean scores reported for a sample labelled "chronic illness" was 89.8. MUIS scores reported for specific chronic ilinesses include: 88.3 for chronic airway obstruction, 92.6 for ischemic heart disease, 89.0 for multiple sclerosis (Mishel \& Epsteln, 1990).

In comparison to other MUIS data, this study's all-male sample, with an average age over 65 years, indicated higher levels of percelved uncertainty than other 
comparable samples. The reported mean score for a sample of 464 men was 81.0 (Mishel \& Epstein, 1990). In age comparisons, the reported mean score for a sample over age 61 was 79.0 . This sample's total score mean was also higher than similarly educated groups as well. The mean MUIS score for a sample who finished grades 7 through 12 , was 81.0 (Mishel \& Epstein, 1990). Analysis of Internal Consistency The MUIS data obtained from this sample did not exhibit the moderate to high levels of internal consistency that other research has obtained. Chronbach's alpha was used to analyze the reliability of the MUIS for this sample. Results showed an alpha of .7840 for the total scale. The subscales produced the following reliability information:

1. Factor 1 (Ambiguity) produced an alpha of .8301.

2. Factor 2 (Complexity) produced an alpha of .7183.

3. Factor 3 (Deficient information) produced an alpha of .2150

4. Factor 4 (Unpredictability) produced an alpha of .4837.

In the literature accompanying the MUIS, Dr. Mishel suggests that researchers use the four-factor form of the MUIS. This 34-item scale can be recalculated to a two 
factor, 28-item version which has been shown to produce better reliabilities in some studies. Even when the data was calculated to the two-factor form, the reliability coefficient for the total scale was .789 . The coefficient alpha for the first factor, ambiguity, was .723 and was .462 for the second factor, complexity.

Data from uncertainty research in other chronic illness populations, while lower than the reliabilities from hospitalized medical and surgical patients, produced alpha levels of .88 for factor $1 ; .60$ for factor $2 ; .81$ for factor 3; and .62 for factor 4 (Mishel \& Epstein, 1990). The small sample size of this study may have contributed to lower internal consistency figures. The samples used to calculate the reliabilities of the MUIS for both chronic and acute illnesses were much larger. Analysis Related to the Research Questions

The following section reviews statistical findings in relation to each research question. Correlations are briefly outlined in Table 3 .

1. The first research question was: "Is there a relationship between uncertainty in illness and the frequency of performance of self-blood glucose monitoring in non-insulin dependent diabetic men?" A Pearson product-moment correlation was used to evaluate for the 


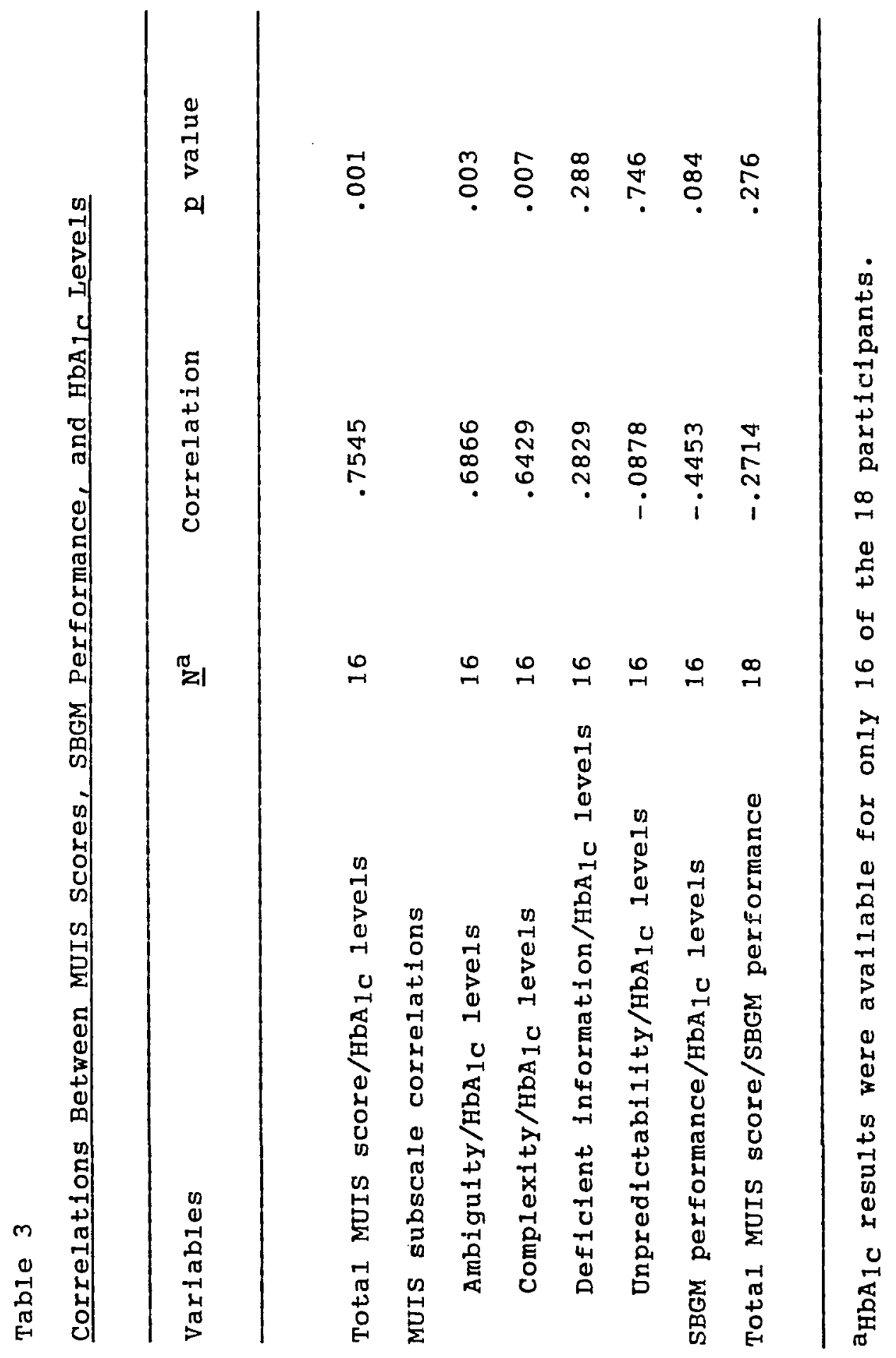


presence and direction of a relationship. Testing was done using the total MUIS score, and each of the four subscale scores, as the independent variable to determine if there were differences in results.

No statistically significant relationship was found between the total MUIS score and the frequency with which self-blood glucose monitoring was performed. A weak, non-significant $(\underline{r}=-.2714, \underline{p}=.276)$ negative correlation was obtained in this analysis. Furthermore, no significant relationships were found between any of the MUIS subscales and the frequency of self-blood glucose monitoring.

2. The second research question was: "Is there a relationship between uncertainty in 11 lness and the adequacy of glycemic control in non-insulin dependent diabetic men?" Results indicated a statistically significant relationship between the MUIS $(\underline{r}=.7545$, $p=.001)$ as illustrated in Figure 1. The relationships found in this analysis are in the positive direction, because higher MUIS scores are accompanied by higher glycosylated hemoglobin leve1s.

The ambiguity subscale showed a statistically significant, positive correlation with glycemic control with $\underline{r}=.6866(\underline{p}=.003)$. The complexity subscale also showed a significant positive correlation with glycemic 


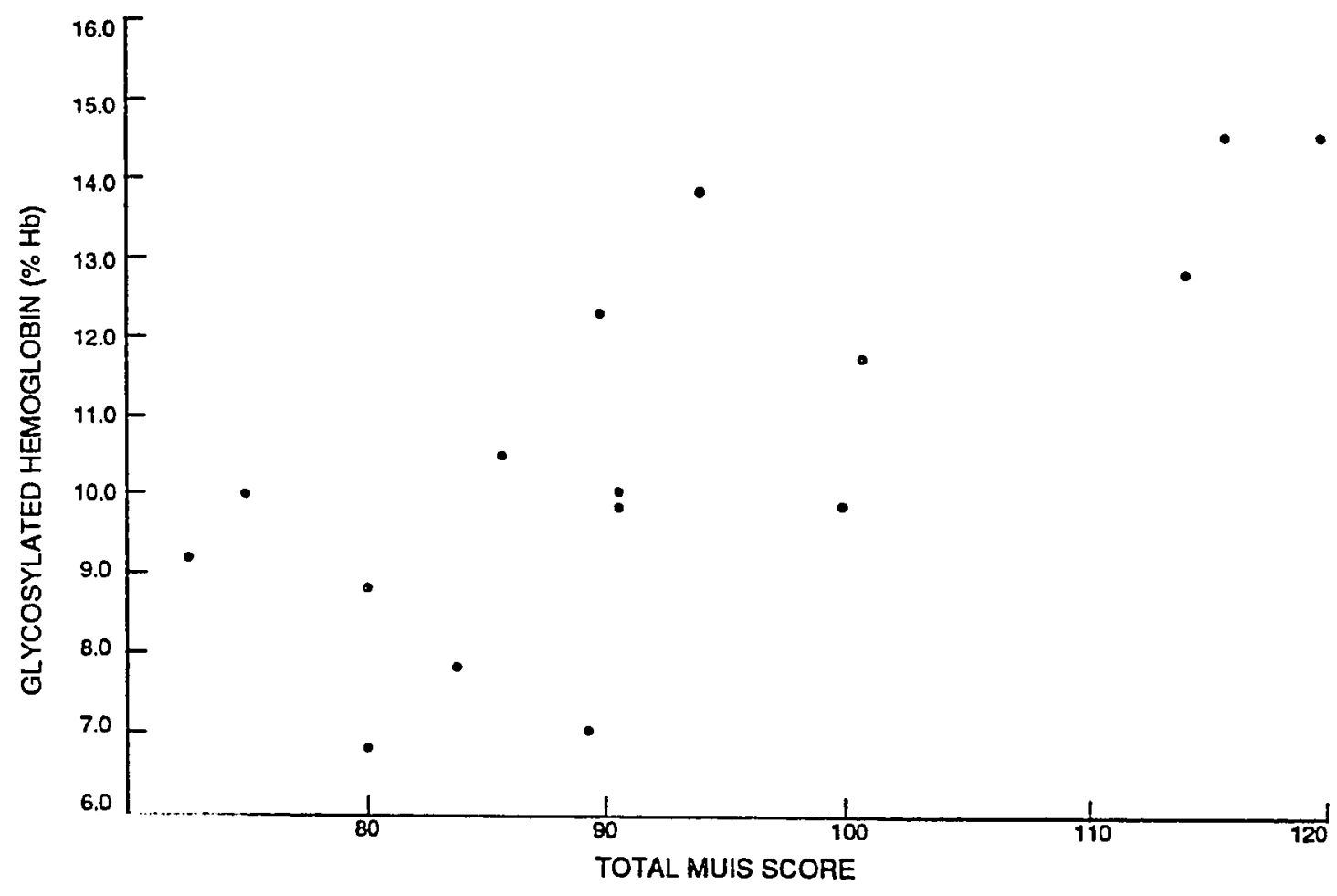

Eigure 1. Relationship of MUIS Scores and Glycosylated Hemoglobin. 
control with $\underline{\underline{r}}=.6429(\underline{\underline{ }}=.007)$. The deficient information and unpredictability subscales did not produce significant results.

3. The third research question was: "Is there a relationship between frequency of self-blood glucose monitoring and glycemic control in non-insulin dependent diabetic men?" The relationship between glycosylated hemoglobin levels and self-blood glucose monttoring was in the negative direction, and approached but did not quite attain significance. The correlation, as illustrated in Figure 2, was $-.4453(\underline{p}=.084)$ for these variables. However, when one aberrant case was eliminated, the correlation increased substantially $(\underline{\underline{r}}=-.764, \underline{p}=.001)$.

It is not an acceptable practice to remove cases because they do not yield desirable results. However, the large increase in the value of the correlation indicates that perhaps there is a significant correlation, but the sample size was not enough to detect it. For the present, however, judgement must be suspended pending further study. 


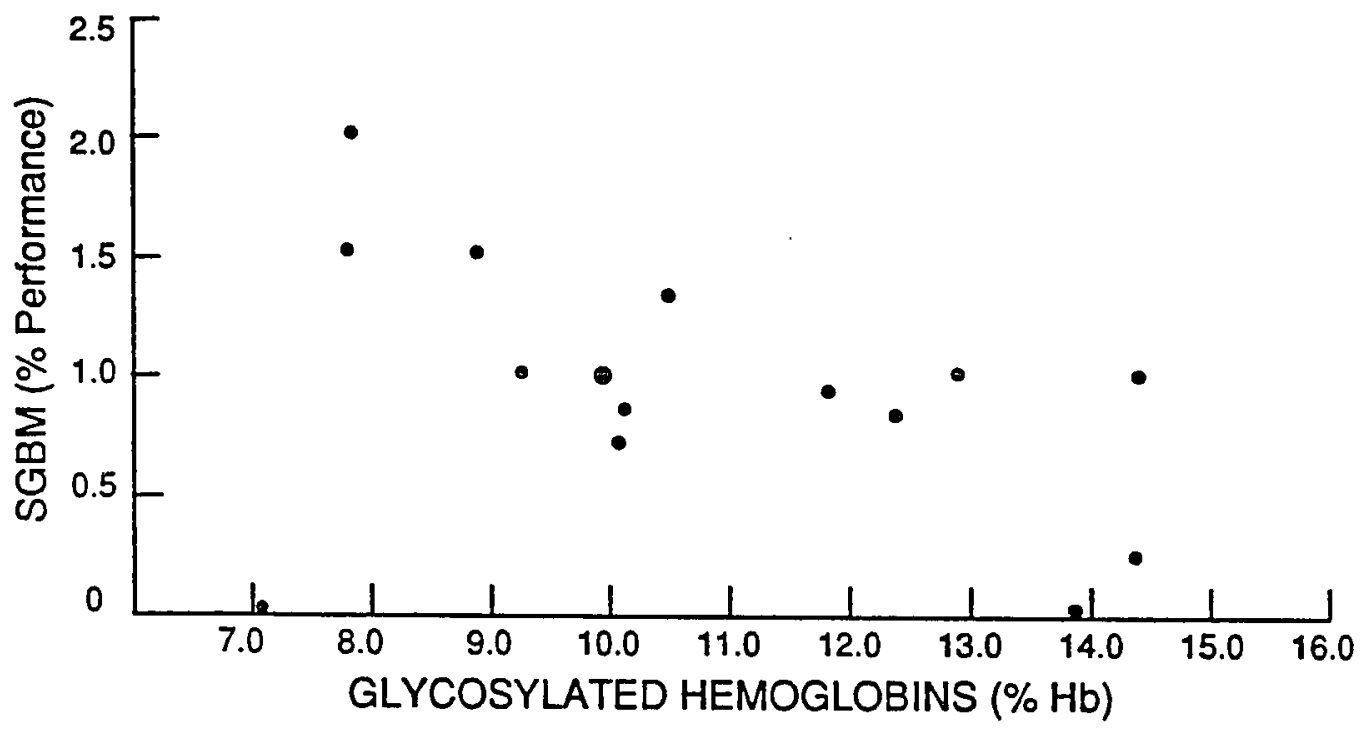

Fiqure 2. Relationship of Glycosylated Hemoglobin and Performance of Self-blood Glucose Monitoring. 


\section{Chapter 5}

\section{CONCLUSIONS AND RECOMMENDATIONS}

Summary of Major Findings

This study explored the relationships between

perceived uncertainty in 11lness, self-blood glucose

monitoring, and adequacy of glycemic control in non-insulin

dependent diabetic men. Findings indicate no significant

relationship between the level of perceived uncertainty in

illness and the frequency of self-blood glucose monitoring

in this sample. Analysis also failed to show a

significant relationship between the frequency of

self-blood glucose monitoring and adequacy of glycemic

control in the sample. However, the trend of data, as

illustrated in Figure 2, suggests the possibility that

significant relationship exists.

A highly significant relationship was found between

the level of perceived uncertainty in illness and the

adequacy of glycemic control in this sample. This was a

positive relationship because as the level of uncertainty

increased, there was a corresponding increase in the

glycosylated hemoglobin value.

These findings which indicate a stronger link between attitudes about health and physiologic functioning, than between attitudes and health-related behaviors are similar 
to those obtained in previously mentioned research by Harris and Linn (1985) and Harris, et al. (1982).

Harris and Linn speculate that the physiologic response between body and mind may account for patients with positive attitudes having more optimal glycemic control than those with a pessimistic or a negative attitude. They explain that anxiety and stress produced from the negative attitude may result in decreased insulin production and increase catecholamine and cortisol levels. These chemical responses could directly influence metabolic control (Harris \& Linn, 1985).

It is possible that the anxiety or stress produced from perceived uncertainty may have similar effects. Another possibility is that the more uncertain one is about the ability to control the course or outcome of iliness, the more one may feel that the future is inevitable regardiess of management strategies. Since behaviors, such as following a diet or taking medications are perceived as having little significance in terms of outcome they may be given less priority over other lifestyle cholces. This too may influence glycemic control.

The fallure to produce a significant relationship between adherence to prescribed behaviors and adequacy of glycemic control has also been reported other research 
studies. Glasgow, McCaul, and Schafer's 1987 study of insulin-dependent diabetics found no clear link between regimen adherence and metabolic control. They suggest that adherence must be viewed in the context of all factors that might contribute to metabolic control such as stress, individual metabolic factors, and appropriateness of regimen prescription rather than assuming a one-to-one relationship between adherence and control (Glasgow et al., 1987).

These findings are not unanimous in the literature, however. Some studies found stronger relationships between diabetics' attitudes toward health and their health-related behaviors than between diabetics' health attitudes and their physiologic control (Peterson, McLean, \& Senator, 1987).

Explanation of Results from the Perspective of the Conceptual Framework

The Trajectory Framework, presented in Chapter 2 of this paper, describes a reciprocal influence between the i11 person's experiences in illness, his behaviors, and the course and outcome of the iliness (Corbin \& strauss, in press). Through this reciprocal impact, the course of the iliness is shaped. 
One way this shaping occurs is through the development of a trajectory projection, a mental vision of the future effects of the illness and its treatment on personal, family, social, and career life. This projection is the basis for the formation of a trajectory scheme, by which one envisions or plans how he w11l manage the tasks related to the illness as well as other daily living tasks. The findings of this study demonstrate several concepts described in the Trajectory Framework. For example, the strongly significant relationship between uncertainty and glycemic control may indicate that the perception of uncertainty represents one of several possible aspects of trajectory projection. The uncertainty may in turn have a reciprocal influence on blood glucose levels, and may ultimately shape the outcome of the illness.

The direction of the relationship between adherence to self-blood glucose monitoring and glycemic control also indicates a trend of shaping the course of diabetes. While the limitations of these findings must be considered, the indications are that behaviors, such as self-blood glucose monitoring, represent one aspect of the trajectory scheme. The practice of this monitoring may in turn influence blood glucose levels and may likewise shape the illness outcome. 
Iimitations to Generalizability

The value of this study in illustrating the previous concepts must be weighed against possible limitations. One such limitation is the small convenience sample utilized in this research. One can only infer that the relationships presented are valid for this group of elderly, male diabetics who attend this clinic.

Furthermore, the data provided in this study do not offer evidence of cause and effect between perceived uncertainty and adequacy of glycemic control in non-insulin dependent diabetics. Many things can be correlated without having a cause and effect relationship. Data linking these concepts using the Pearson product-moment correlation can only be viewed as having potential for some stronger relationship.

Another limitation to the generalizability of this study is the low degree of internal consistency achieved in the MUIS scores for this sample. This may have been a result of the small sample size, or may reflect the need for a tool that reflects the experience of uncertainty specific to diabetics in an outpatient setting. Recommendations

Non-insulin dependent diabetes is a known cause of many life-altering and life-threatening complications. The 
occurrence of these complications is believed to be associated with adequacy of blood glucose control. Nursing interventions to improve glycemic control may decrease the occurrence or reduce the severity of the long and short term complications.

Findings of this study indicate that patients' degree of uncertainty regarding their iliness may influence the adequacy of glycemic control. Implications for nursing research and practice include the following:

Regarding the suggested relationship between perceived uncertainty and glycemic control, research studies might focus on interventions to decrease the level of uncertainty in the NIDDM population. Patient education programs that cover the pathophysiology of diabetes and that give the rationale for each prescribed treatment might be tested for their influence on the perception of uncertainty.

Furthermore, diabetes requires day-to-day management decisions that influence (and are influenced by) daily life circumstances. For example, decisions must be made regarding the insulin dose if one has a fever, or is nauseated and can not eat regular meals. Decisions must also be made if the self-blood glucose reading is very high or very low. Research could be conducted to see if a support network to share problem-solving strategles influence either uncertainty or the level of blood glucose control. 
This study was conducted using a very small convenience sample of 18 NIDDM adult men. Research with a much larger, representative sample might more accurately determine if the relationship between percelved uncertainty and adequacy of glycemic control extends to the diabetic population.

Further research is also needed to explore why this study failed to find relationships between percelved uncertainty and self-blood glucose monitoring (SBGM) and between SBGM and glycemic control. Perhaps qualitative studies could be conducted to explore what uncertainty means to middle-aged or older diabetics. Studies are also needed to understand attitudes and motivators of self-care in older diabetics. For instance, Price's (1988) sample ranged between the ages of 24 to 53 , while this sample's mean age was 65.81 years. It is possible that the experience of uncertainty and the attitudes or motivators to self-care may differ between these two age groups.

Research to evaluate NIDDM patients' knowledge and skills in the use of self-blood glucose monitoring is also recommended. One of the important uses of SBGM is to provide immediate feedback on day-to-day blood glucose control decisions. Knowledge or skill in interpreting SGBM was not measured in this sample. Perhaps a knowledge 
deficit prevented an effective use of the home blood testing results.

Furthermore, SBGM is only one aspect of a diabetic's care regimen. It may be important to explore the relationship of uncertainty to glycemic control and adherence to other care prescriptions. It may be that the links between uncertainty and commitment to diet, exercise, or medication use are more important in influencing blood glucose levels than those between uncertainty and self-blood glucose monitoring.

The results of this study suggest that uncertainty may be an significant influence on the adequacy of blood glucose control in non-insulin dependent diabetics. Therefore, further studies of uncertainty and its possible behavioral and physiological effects may provide the basis for interventions which enhance diabetic management and improve patients' chances of avoiding long term complications. 
REFERENCES 
References

American Diabetes Association. (1985). Self-monitoring of blood glucose: A policy statement. Diabetes Care, $8(5)$, 515.

Bidnick, M. (1986). The relationship between perceived uncertainty and adaptation to chronic low back pain. Unpublished master's thesis, University of Kansas. Budner, S. (1962). Intolerance of ambiguity as a personality variable. Journal of Personality, 30, 29-50. Cerkoney, K. A. B., \& Hart, L. K. (1980). The relationship between the health belief model and compliance of persons with diabetes mellitus. Diabetes Care, $\underline{3}(5)$, 594-598.

Christensen, N. K., Terry, R. D., Wyatt, S., Pichert, J. W. \& Lorenz, R. A. (1983). Quantitative assessment of dietary adherence in patients with insulin-dependent diabetes mellitus. Diabetes Care, $\underline{6}, 245-250$.

Christman, N. J., McConnel1, E. A., Pfeiffer, C., Webster, K. K., Schmitt, M., \& Ries, J. (1988). Uncertainty, coping, and distress following myocardial infarction: Transition from hospital to home. Research in Nursing \& Health, 11, 71-82.

Corbin, J., \& Strauss, A. (1988). Unending work and care: Managing chronic iliness at home. San Francisco: Jossey-Bass. 
Corbin, J. M., \& Strauss, A. (in press). A nursing model for chronic illness management based upon the trajectory framework. Scholarly Inquiry for Nursing Practice. DeVon, H. A., \& Powers, M. J. (1984). Health beliefs, adjustment to iliness, and control of hypertension. Research in Nursing \& Health, Z, 10-16.

Dieh1, A. K., Bauer, R. L., \& Sugarek, N. J. (1987). Correlates of medication compliance in non-insulin dependent diabetes mellitus. Southern Medical Journal, $\underline{80}(3), 332-5$.

Dunbar, J. M., \& Strunkard, A. J. (1979). Adherence to diet and drug regimen. In B. Dennis \& N. Ernst (Eds.), Nutrition, lipids, and coronary heart disease (pp. 391-423). New York: Raven Press.

Ekerling, I. \& Kohrs, M. B. (1984). Research on compliance with diabetes regimens: Applications to practice. Journal of the American Dietetic Association, 84, 805-809.

Forsyth, G. I., Delaney, K. D., Gresham, M. I. (1984). Vying for a winning position: Management style of the chronically 11l. Research in Nursing \& Health, I, $181-188$. 
Fox, M. A., Cassmeyer, V., Eaks, G. A., Hamera, E.,

O'Connell, K., \& Knapp, T. (1984). Blood glucose

self-monitoring usage and its influence on patients'

perceptions of diabetes. The Diabetes Educator, 10(3), $27-31$.

Froesch, E. R., Assal, J., \& Liniger, C. (1986). Diabetes mellitus: Physlology and pathophysiology of glucose, fat, and ketone metabolism. In A. Labhart (Ed.), Clinical endocrinology: Theory and practice (pp. 756-848). New York: Springer-Verlag.

Gilden, J. I. (1988). Benefits from self-monitoring of blood glucose. Consultant, 28(1), 29-32, 34 . Glasgow, R. E., McCaul, K. D., \& Schafer, I. C. (1987). Self-care behaviors and glycemic control in type I diabetes. Journal of Chronic Disease, 40(5), 399-412. Glasgow, R. E., Wilson, W., \& MCCaul, K. (1985). Regimen adherence: A problematic construct in diabetes research. Diabetes Care, $8(3), 300-301$.

Haefner, D. P. \& Kirscht, J. P. (1970). Motivational and behavioral effects of modifying health beliefs. Public Health Reports, $85,478-482$.

Hamera, E., Cassmeyer, V., O'Connell, K., Weldon, G. T., Knapp, T. M., \& Ryner, J. L. (1988). Self-regulation in individuals with type II diabetes. Nursing Research, $\underline{37}(6), 363-367$. 
Harris, R. \& Linn, M. W. (1985). Health beliefs, compliance, and control of diabetes mellitus. Southern Medical Journal, $78(2), 162-166$.

Harris, R., Skyler, J. S., Linn, M. W., Pollack, L., \& Tewksbury, D. (1982). Relationship between the health belief model and compliance as a basis for intervention in diabetes meliftus. Pediatric Adolescent Endocrinology, 10, 123-132.

Korhonen, T., Huttunen, J. K., Aro, A., Hentinen, M., Thalainen, 0., Majander, H., Siitonen, 0., Ousitupa, M., \& Pyorala, K. A. (1983). A controlled trial on the effects of patient education in the treatment of insulin-dependent diabetes. Diabetes Care, $\underline{6}, 256-261$. Mishel, M. H. (1981). The measurement of uncertainty in illness. Nursing Research, $\underline{30}(5), 258-263$.

Mishel, M. H. (1984). Perceived uncertainty and stress in illness. Research in Nursing \& HeaIth, I, 163-171. Mishe1, M., \& Epstein, D. (1990). Uncertainty in illness scales. Manual. (Available from Merle Mishel, Ph.D., R.N. College of Nursing, University of Arizona, Tucson, $\mathrm{AZ}, 85721)$.

Peterson, G., Mclean, S., \& Senator, G. (1984). Determinants of patient compliance, control, presence of complications, and handicap in non-insulin dependent diabetes. Australian and New Zealand Journal of Medicine, 14(2), 135-141. 
Price, M. J. (1988). Perceived uncertainty associated with the management trajectory of a chronic illness: Diabetes mellitus. Unpublished doctoral dissertation, University of California, San Francisco.

Sackett, D. L. \& Snow, J.C. (1979). The magnitude of compliance and non-compliance. In R. B. Haynes, D. W. Taylor, \& D. L. Sackett (Eds.), Compliance in health care (pp. 11-22). Baltimore: The Johns Hopkins University Press.

Saucier, C. P. (1984). Improvement in long-term control of chilören performing blood glucose self-monitoring. The Diabetes Educator, $10(3), 33-35$.

Schafer, L. C., Glasgow, R. E., McCaul, K. D., \& Dreher, M. (1983). Adherence to IDDM regimens: Relationship to psychosocial variables and metabolic control. Diabetes Care, $\underline{6}, 493-498$. Sjoberg, S., Carlson, A., Rosenqvist, U., \& Ostman, J. (1988). Health attitudes, self-monitoring of blood glucose, metabolic control, and residual insulin secretion in type 1 diabetic patients. Diabetic Medicine, $\underline{5}(5), 449-453$.

Skelton, C. W. (1986). Use of glycosylated hemoglobins in the long-term management of diabetes. Nurse Practitioner, $11(3), 46-48$. 
Suls, J., \& Mullen, B. (1981). Life events, perceived control and illness: The role of uncertainty. Journal of Human Stress, $\underline{Z}(2), 30-34$.

Tchobroutsky, G. (1978). Relationship of diabetic control to development of microvascular complications. Diabetologia, 15, 143-152.

Webster, K. K.., \& Christman, N. J. (1988). Perceived uncertainty and coping post myocardial infarction. Western Journal of Nursing Research, 10(4), 384-400. Williams, T. F., Anderson, E., Watkins, J. D., \& Coyle, V. (1967). Dietary errors made at home by patients with diabetes. Journal of the American Dietetic Association, $\underline{5} 1,19-25$.

Wilson, W., Ary, D. V., Biglan, A., Glasgow, R. E., Toobert, D. J., \& Campbell, D. R. (1986). Psychosocial predictors of self-care behaviors (compliance) and glycemic control in non-insulin dependent diabetes mellitus. Diabetes Care, $9(6), 614-622$.

Wing, R. R., Epstein, L. H., Nowalk, M. P., Scott, N.\& Koeske, R. (1985). Compliance to self-monitoring of blood glucose: A marked-item technique compared with self-report. Diabetes Care, $8(5), 456-460$. 
APPENDIX A

Human Subjects Approval

Stanford University 
STANFORD UNIVERSITY

St onford, Colifornio 94305

(415) $723-2883$

CERTIFICATION OF HUMAN SUBJECTS APPROUAL

DATE: November 7,1989

TO: K.M. Brown, RN

Department of Nursing

FROM: Chasrman, Administrative Panel

on Human Subjects in Medical Reseoreh

PROTOCOL TITLE:

Effects of Uncertainty in Illness on Self-Monitoring of Blood Glucose and

Glycemic Control in Non-Insulin Dependent Diabetics

The Panel approved humen subjects involvement in your researeh project on November 7, 1989.

The expiration date of this approval is November 6, 1990. If this project is to contanue beyond that date, please submit an updated proposal in advance for the Panel's re-approval. If this proposal is used in conjunction with any other human experimentation or if it is modified $2 n$ any way, it must be reopproved for these speciol carcumstances. In addition. the Panel requests prompt notification of any complications which moy occur during any experimental procedure.

All continuing projects and activities must be reviewed and re-approved at least annually by the Panel. Panel approval of any project is for a maximum perlod of one year. It 15 the responsibllity of the investigator to resubmit the project to the Panel for annual review.

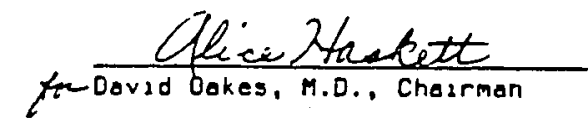

ce: Sponsored Projects

Helen Dov15, RN MS

D. Lockard. ACNSR

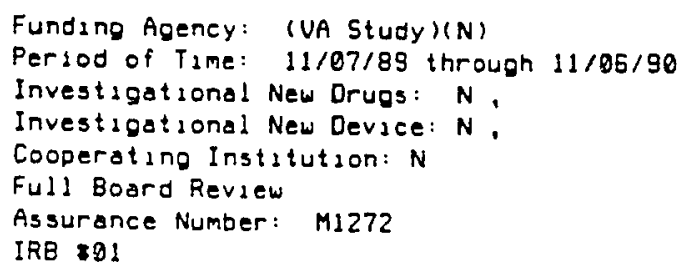


APPENDIX B

Institutional Review Board Approval

San Jose State University 


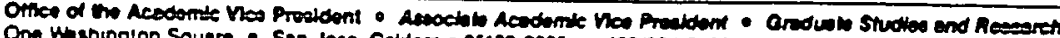

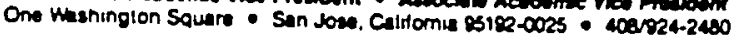

To: Reren H. Brown, Nursing

2578 Sierra vista Court

San Jose, CA, 95116

From: Charles R. Bolz

Office of Graduate studies and Research

Date: Apri1 23, 1990

The San Jose State University Human Subjects Institutional Review Board has accepted your stanford University Human Subjects Institutional Review Board approval to use human subjects in the study entitled:

"Effects of Uncertainty in Iliness on SelfMonitoring of Blood Glucose and Glycemic Control in Non-Insulin Dependent Diabetics"

This approval is contingent upon the subjects participating in your research project being appropriately protected from risk. The Board's approval includes continued monitoring of your research by the Board to assure that the subjects are being adeguately and properly protected from ouch risks. If at any time a mubject becomes injured or complains of injury, you must notify Dr. Serena stanford immediately. Injury includes but is not Iimlted to bodily harm, peychological trauma and release of potentialiy damaging personal information.

Please also be advised that each subject needs to be rully informed and aware that their participation in your research project is voluntary, and that he or the may vithdraw from the project at any time. Purther, a subject's participation, refusal to partlcipate or withdrawal will not affect any services the subject is receiving or will receive at the institution in which the research is being conducted. This approval is subject to the time restrictions imposed by your submitted HSIRB approval and will expire on the same date.

If you have any questions, please contact Dr. Stanford or me at (408) $924-2480$.

cc: Juliet M. Corbin, Ph.D. 
APPENDIX C

Consent Letter 


\section{INPORMED CONSENT}

You are invited to participate in a otudy of uncertalnty in illness in

diabetes self-care and blood glucose control. I hope to learn if a

relationship exdsts betveen the level of uncertainty in illsess and level of adherence to self-monitoring of blood glucose and blood glucose control in diabetics. You vere selected as a possible participant in this study because you have diabetes. If you decide to particlpate, I vill ask you questions about the frequency that you test your blood glucose at home, and some other questions about yourself such as age, level of education, warital status, income, race, and medical diagnoses. Finally, I vill give you a questionnaire to fill out that measures the amount of uncertainty you wy feel about your diabetes or fts treatment. I w11l also obtain the results of your most recent glycosylated henoglobln level (which is an indicator of giucose control over an extended period of time) that vas drawn here at the V.A. I vill use only lab results that vere obtained as a part of your regular treatment here, and will not ask you to undergo any additional lab tests just for the purpose of this study. No personal medical risks or benefits are expected as a result of this study. Hovever, this study may benefit diabetics in general by increasing our level of knouledge of the experience of uncertainty on people who have diabetes. The interviev and questionnaire is expected to take 30 to 60 minutes of your time, and will require no further work or follow-up by you. I CANNOT AND DO NOT GRRANTEE OR PROMISE THAT YOU WILL RECETVE NNY BDNEFITS FROM THIS STUTY.

$\begin{array}{ll}\text { Signature of participant } & \text { Date } \\ \text { Signature of Investigator or vitness } & \text { Date }\end{array}$


EFFECTS OF UNCERTAINTY IN ILLNESS ON SELF-MONITORING OF BLOOD GUCOSE AND GLYCEMIC CONIROL IN NON-INSULIN DEPENDENT DIABETICS

Any data that ma be published in scientific joumals wll not reveal the identity of the subjects. As this study is being conducted as part of my graduate nursing program at San Jose State University, the information I collect will be shared with wy three faculty thesis advisors. This data will also be shared with Dr. Merle Mishel of the Oniversity of Arizona College of Mursing, who developed the Uncertainty in Illness scale. The Identity of Indivioual subjects vill not be shared with wy faculty of with Dr. Mishel. In the interest of public safety, patient information will be provided to Federal and regulatory agencies as reguired. No payment will be provided for this project. There will be no additional cost to you for participation in this study.

Your decision whether or not to participate will not prejudice you or your medical care. If you decide to participate, you are free to vithdraw your consent and to discontinue participation at any time without prejudice to you or effect on your medical care. If you have any guestions, I expect you to ask me. If you have additional questions later, I will be happy to answer them. My phone number is (408) 353-4477. Complaints about the procedures may be presented to IIy thesis advisor, Dr. Juliet Corbin of San Jose State University, 924-3155. For questions or complaints about research subjects rights, or in the event of research-related injury, contact serena stanford, Ph.D. (Associate Academic Vice President for Graduate Studies \& Research) at 924-2480.

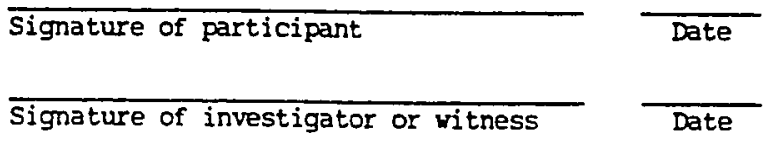


EFFDCTS OF UNCERTAINTY IN ILLNESS ON SELF-MONITORING OF BLOOD GLCOSE AND GLYCEMC CONIROL IN NON-INSULIN DEPENDENT DIABETICS

All forms of medical diagnosis and treatrent--whether routine or experimental-imvolve some risk of injury. In spite of all precautions, you might develop sedical cooplications from participating in this study. If such canplications arlse, the researcher will assist you in obtaining approprlate medical treatment, but this study does not provide financial assistance for additional medical or other costs. Additionally, Stanford is not responsible for research and medical care by other institutions or personnel particlpating in this study. You do not watve any legal rights by signing this form. For further information, please call (415) 723-5244 or write the Medical Comittee for the Protection of Human Subjects at Medical School offlce Bullding, Rocm C-051, Stanford, California, 94305. In addition, If you are not satisfied w th the wanner in which this study is being conducted, you may report any complaints to the same telephone number and address.

YOUR SIGNATURE INDICATES THAT YOU HAVE READ AND LNDERSTAND THE ABOVE INPORMATION, THAT YOU HAVE DISCUSSED THIS STUDY WITH THE PRTNCIPAL INVESTIGATOR AND HIS OR HER STAFF, THAT YOU HAVE DECIDED TO PARTICIPATE BASED ON THE INFORMATION FROVIDED, AND THAT A COFY OE THIS FORM HAS BEDN GIVEN TO Yoग.

Signature of participant

Signature of investigator or witness

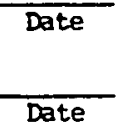


EFFECTS OF UNCERTAINTY IN ILLNESS ON SELF-MONITORING OF BLOOD GLUCOSE AND GLYCEMIC CONTROL IN NON-INSULIN DEPENDENT DIABETICS EXPERTMENTAL SUBJECTS BILL OF RIGHTS

Persons who participate in a medical experiment are entitled to certain

rights. These rights include but are not ilmited to the subject's right to: be informed of the nature and purpose of the experiment; be given an explanation of the procedures to be followed in the medical experiment, and any drug or device to be utilized; be given a description of any attendant discomforts and risks reasonably to be expected; be given an explanation of any benefits to the subject reasonably to be expected, if applicable; be given a disclosure of any appropriate alternatives, drugs or devices that might be advantageous to the subject, their relative risks and benefits; be informed of the avenues of medical treatment, if any available to the subject after the experiment if corplications should arise; be given an opportunity to ask questions concerning the experiment or the procedures involved; be instructed that consent to participate in the medical experiment may be withdrawn at any time and the subject way discontinue participation without prejudice; be given a copy of the signed and dated consent form; and be given the opportunity to decide to consent or not to consent to a medical experiment without the intervention of any element of force, fraud, deceit, duress, coercion or undue influence on the subject's decision,

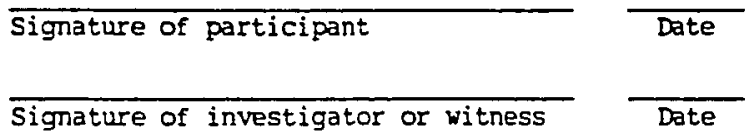


APPENDIX D

Interview/Questionnaire Form 
No.:

Date:

Uncertainty In Illness Study Interview Form

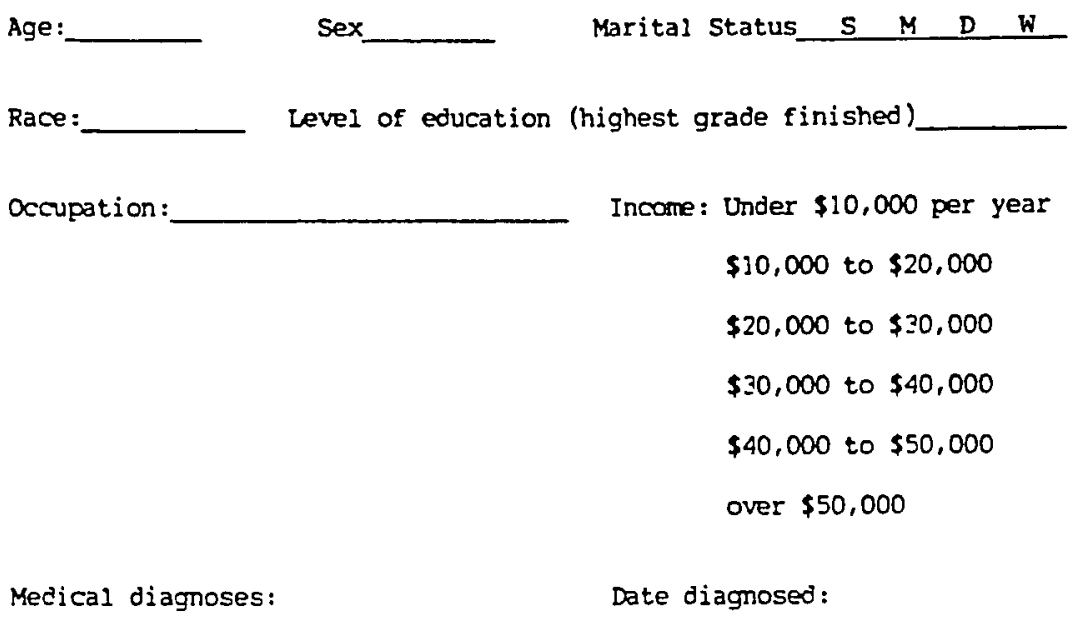

Mecications and care prescriptions:

Number of home blood glucose tests performed in past 7 days: Results of most recent glycosylated hemoglobin

Date drawn 
APPENDIX E

Mishel Uncertainty in Illness Scale 
PLEASE NOTE

\begin{abstract}
Copyrighted materials in this document have not been filmed at the request of the author. They are available for consultation, however, in the author's university library.
\end{abstract}

$77-80$

University Microfilms International 


\section{APPENDIX F \\ Permission to use the Mishel Uncertainty in Illness Scale}


I requeat permiabion to copy the Adult Uncerteinty in Illneso Scale for uoe in my reaearch entitied, Effects ef uncertainty in Illness n.?

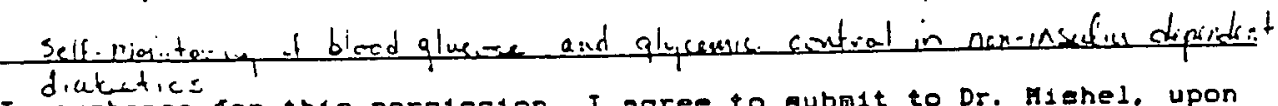
In exchange for this permiagion. I ggree to aubnit to Dr. Hiahel. upon completion of the etudy e printout of the uncertainty dete or $5 x$ inch dise dictionary. The dote muet contein

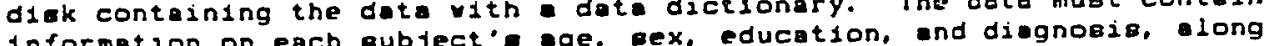
Informetion on each oubject ege, eex, education, dota vill be ueed to wth the ray data on the uncerteinty cese. Thical populations. No other use establish normative data base for clinical populations. No other $\checkmark 211$ be made of the data eubmitted. Credit uae of the data I oubmitted reports of normative etatiotica thet make use of the data 1 aby of $m y$ for pooied awalyoes. I lec agree to and Dr. Miahel copy ol findings. I understand thet my report vilin 11 inese. Credit vall be informbtion on the theory of uncertainty in ilinese.
given to me in any reporta referring to my indings.
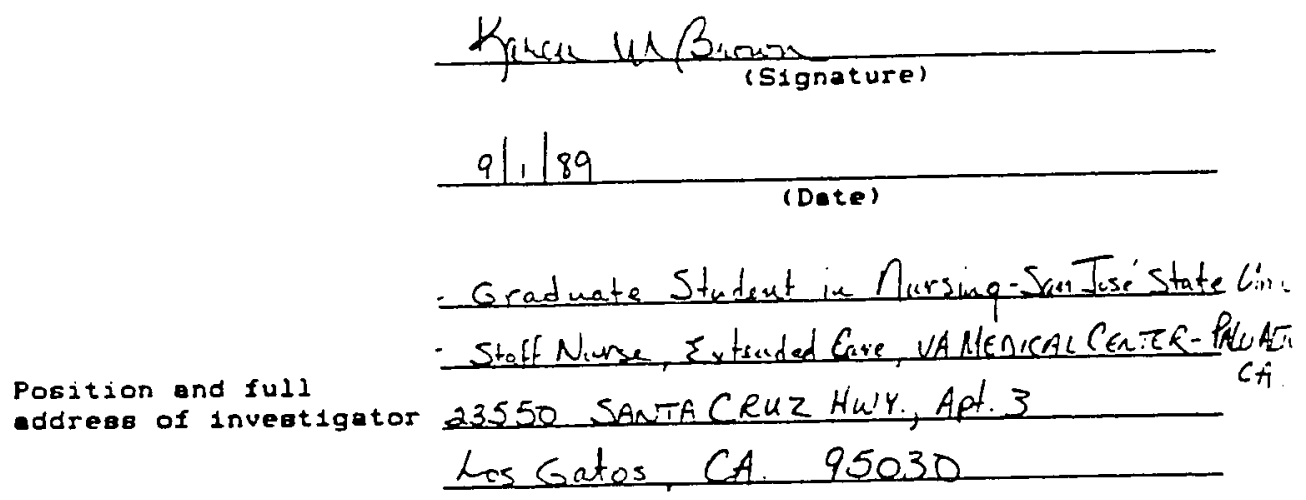

Permigaion 1a hereby granted to copy the nuIs for use in the research described above.

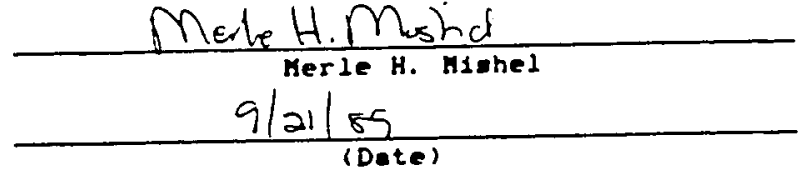

Please aend tro algned copies of this form to:

Kerle H. Mishel, Ph. D.

College of Muraing

Univeraity of Arizona

Tuceon, Arizone, B5721

AHM : $p$ Y

reviaed: $1 / 89$ 